\title{
Taurine newborn screening to prevent one form of retinal degeneration and cardiomyopathy
}

\author{
Stylianos E. Antonarakis ${ }^{1}{ }^{1}$
}

Received: 29 April 2020 / Revised: 29 May 2020 / Accepted: 9 June 2020 / Published online: 22 June 2020

(c) European Society of Human Genetics 2020

In a consanguineous family from Pakistan, we have recently showed that a homozygous Gly399Val pathogenic variant in the taurine transporter gene SLC6A6 causes autosomal recessive retinal degeneration and cardiomyopathy [1]. The blood taurine levels in the two affected individuals were extremely low (hypotaurinemia), and the phenotype was likely due to the deficient intracellular transport of taurine. After 24 months of daily oral taurine supplementation, the cardiomyopathy disappeared and the retina degeneration was arrested in the younger affected sibling; the older affected sibling had completely destroyed retina before treatment. A similar family was also described with a homozygous Ala78Glu variant in the SLC6A6 gene; however, no taurine supplementation was introduced [2]. A third consanguineous family with retinal degeneration was recently identified with a homozygous missense variant (C. Rivolta, University Hospital Basel). The collective pathogenic allelic frequency of the SLC6A6 gene in outbred populations using the whole genome sequencing data of 62,000 individuals from the TOPmed project [3] is 1 in 189 alleles. These are likely loss of function and non-synonymous substitutions with pathogenicity score CADD $>18$. Assuming that all of these variants in homozygosity or compound heterozygosity will lead to severe hypotaurinemia, we estimate that the number of affected individuals (in outbred populations with random mating) is 1 in 35,721 live births. For $130,000,000$ newborns worldwide every year, the estimated number of affected newborns is 3639 (e.g. 258 in EU, USA and Canada combined). In addition, assuming that $5 \%$ of the world population practices consanguinity

Stylianos E. Antonarakis

Stylianos.Antonarakis@unige.ch

1 Department of Genetic Medicine and Development, University of Geneva, Geneva, Switzerland
[4], we also expect an additional 2145 affected newborns per year, and the total number of estimated affected newborns could be $\sim 5800$.

Since taurine could be detected in the Guthrie screening samples, we wish to propose the possibility of a neonatal screening for taurine levels in blood in order to identify children with hypotaurinemia and therefore at high risk for the Mendelian retinal degeneration and cardiomyopathy caused by pathogenic variants in the SLC6A6 transporter. In the case of true positive identification of likely affected individuals/families, we subsequently propose an extensive clinical trial of long-term oral supplementation with $100 \mathrm{mg} / \mathrm{kg} /$ day taurine with the objective to prevent the onset of the symptoms and the progressive degeneration of the retina that leads to complete visual loss.

The discovery of the molecular cause of genetic diseases provides in some cases the introduction of treatments based on the exact molecular defect/pathway; the taurine deficiency case discussed here provides an excellent example and encourages the world efforts to identify the molecular causes of all Mendelian disorders.

\section{Compliance with ethical standards}

Conflict of interest The author declares that he has no conflict of interest.

Publisher's note Springer Nature remains neutral with regard to jurisdictional claims in published maps and institutional affiliations.

\section{References}

1. Ansar M, Ranza E, Shetty M, Paracha SA, Azam M, Kern I, et al. Taurine treatment of retinal degeneration and cardiomyopathy in a consanguineous family with SLC6A6 taurine transporter deficiency. Hum Mol Genet. 2019. https://doi.org/10.1093/hmg/ ddz303.

2. Preising MN, Görg B, Friedburg C, Qvartskhava N, Budde BS, Bonus M, et al. Biallelic mutation of human SLC6A6 encoding the taurine transporter TAUT is linked to early retinal degeneration. 
FASEB J. 2019;33:11507-27. https://doi.org/10.1096/fj.2019009 14RR.

3. Taliun D, Harris DN, Kessler MD, Carlson J, Szpiech ZA, Torres $\mathrm{R}$, et al. Sequencing of 53,831 diverse genomes from the NHLBI TOPMed Program. 2019. https://doi.org/10.1101/563866.
4. Hamamy H, Antonarakis SE, Cavalli-Sforza LL, Temtamy S, Romeo G, Ten Kate LP, et al. Consanguineous marriages, pearls and perils: Geneva International Consanguinity Workshop Report. Genet Med. 2011;13:841-7. https://doi.org/10.1097/GIM.0b013e3 $18217477 f$. 